
3 Research Square
Preprints are preliminary reports that have not undergone peer review.
They should not be considered conclusive, used to inform clinical practice, or referenced by the media as validated information.

\title{
Assessment of linkage between Productive Safety Net Program and Health Services in Somali Region, Ethiopia: Lessons, Challenges and Missed Opportunities
}

\author{
Olusola Oladeji ( $\square$ ooladeji@unicef.org ) \\ UNICEF ETHIOPIA, Somali Field Office \\ Abdifatah Elmi Farah \\ UNICEF ETHIOPIA, Somali Field Office \\ Ann Robins \\ UNICEF Uganda
}

\section{Research Article}

Keywords: Productive safety nets program, linkage, health services, co-responsibilities

Posted Date: October 1st, 2021

DOI: https://doi.org/10.21203/rs.3.rs-952300/v1

License: (c) (1) This work is licensed under a Creative Commons Attribution 4.0 International License. Read Full License 


\section{Abstract}

Background: Ethiopia's Productive Safety Net Programme (PSNP) which has been implemented since 2005 is a large-scale, social protection intervention aimed at improving food security. The fourth phase of the PSNP included a system of integrated health and nutrition service delivery for its categories of beneficiaries especially the creation of a temporary direct support(TDS) category for clients that are pregnant and lactating women (PLW) or caretakers of malnourished children, who are exempted from public work but expected to comply with co-responsibilities which counts towards their public works requirement aimed at improving utilization of health services.

\section{Methods:}

The study was a cross-sectional descriptive survey and used qualitative methods, in-depth interviews and focus group discussions (FGDs), conducted in two woredas( districts) (Gursum and Kebribayah) in Farfan zone of Somali region. The study population were key individuals involved in the linkages of PSNP with health services and the beneficiaries. The study assessed the implementation of the linkage between PSNP4 and health services

Results: The study observed that the stakeholders have adequate knowledge and understood their roles in the linkages between PSNP and the health services, in addition the beneficiaries also are aware of their rights and the process for exemption from public work. However, the major issues identified included poor coordination among the implementing actors, poor knowledge, monitoring and compliance with the co-responsibilities by the stakeholders and the beneficiaries.

Conclusion: Considering the size of the program in the region which is targeted to the poor, the Productive Safety net program being the main tool to help forward Ethiopia's Social Protection Policy and Strategy, has the potential to improve access and utilization of health and nutrition services if more efforts are put to strengthen integration and linkages with the health sector and monitoring of compliance of co-responsibilities by the beneficiaries of the program.

\section{Introduction}

Ethiopia's Productive Safety Net Programme (PSNP) which has been implemented since 2005 is a large-scale, social protection intervention aimed at improving food security. It involves a mix of public works, employment and unconditional cash and food transfers for chronically food-insecure households identified through a mix of geographic and community-based information. The main objective of the PSNP is to increase livelihoods and resilience to shocks and to improve food security and nutrition for vulnerable rural households.

The fourth phase of the PSNP ${ }^{1}$ was launched in 2015 and included a system of integrated health and nutrition service delivery and the creation of a Temporary Direct Support(TDS) category for clients that are pregnant and lactating women (PLW) or caretakers of malnourished children, who are public works clients as part of the several innovations introduced on PSNP4 to enhance programme outcomes, specifically in terms of child nutrition.

The pregnant and lactating women (up to one year after birth) and primary caregivers of malnourished children designated as temporary direct support (TDS) clients are to comply with co-responsibilities which counts towards their public works requirement aimed at improving the health and nutrition of themselves and their children. The co-responsibilities have been introduced for TDS and PDS clients, particularly to strengthen linkages between PSNP with health care services.

These co responsibilities include attendance of four ante-natal consultations, one post-partum health facility visit, uptake of routine immunization, attendance at growth monitoring and promotion, behavioural change communication sessions, monthly check up of the malnourished child at the closest health facility for appropriate treatment.

The effective linkage of PSNP with health services which is aimed at improving maternal and newborn and child health and nutrition outcomes is very relevant and essential in Somali region of Ethiopia which has shown less improvement in key maternal and child health and nutrition outcomes compared to the national average. The 2019 Mini DHS reports that the region has the lowest percentage of fully vaccinated children, with only $18.2 \%$ having received all basic vaccinations, and $48.8 \%$ had received no vaccinations at all compared to national average of $43.1 \%$ and $19.2 \%$ respectively while the proportion of pregnant women who received at least four antenatal care services(ANC4) and delivered by skilled birth attendant is $11.1 \%$ and $26 \%$ compared to national average of $43 \%$ and $49.8 \%$ respectively and post-natal care rate (10.3 per cent). Malnutrition continues to be a serious issue in the region with wasting rate of 22.7 percent compared to $9.9 \%$ national average and contribute to approximately $25 \%$ of the total number of children with wasting in the country. Stunting prevalence in children under 5 years of age stands at 30.5 per cent and 40 per cent of children are exclusively breastfed during the first six months of life, and $18.6 \%$ of pregnant women received Iron Folate. ${ }^{2}$

The available evidences from various studies show that safety nets programs have improved food security, utilization of prevention, promotional and curative health and nutrition services by pregnant women and children, nutritional status of children and health and nutrition education practices. 3,4,5,6,7 However, studies from Ethiopia show mixed impact of PSNP on child nutrition, some studies reported positive impact ${ }^{8,9}$ whereas most studies found no impact on nutrition outcome, utilization of health services by pregnant women for ANC and post-natal care visit and breastfeeding behaviors or nutrition education which are needed for improved maternal newborn and child health and nutrition outcome. $10,11,12,13$

The study aimed to assess the implementation of the linkage between PSNP4 and health services and use the gaps, opportunities and lessons learnt to improve on the implementation of the PSNP 5 for better results for maternal newborn and child health and nutrition outcomes.

\section{Methods}




\section{Study population and setting}

The study was conducted in 2 woredas( districts) (Gursum and Kebribayah) in Farfan zone of the region being the zone with highest number of PSNP beneficiaries in the region.

Kebribeyah woreda has estimated total population of 130,763, 5 health centers and 33 health posts while Gursum woreda has estimated total population of $39,375,3$ health centers and 16 health posts. The total number of PSNP 4 beneficiaries in the region is 1,673,009; Kebribayah woreda has the largest caseload of beneficiaries of 84,977 while Gursum woreda in the same zone has one of the lowest caseloads of 18,245 beneficiaries.

The study population were key individuals involved in the linkages of PSNP with health services at the regional, woreda and kebele levels and the beneficiaries identified based on the World Bank's framework on accountability. ${ }^{14}$

Study Design: The study was a cross-sectional descriptive survey and used qualitative methods

\section{Sampling Technique:}

Multistage sampling technique was used. In the first stage, two woredas and regional level bureaus were selected purposely, Kebribeyah woreda which has the highest caseload of beneficiaries in the region and Gursum woreda which has one of the lowest caseloads in the same zone( Farfan) with Kebribeyah woreda.

In the second stage, three kebeles(sub-districts) from each of the two purposely selected woredas (districts) were selected randomly from among the total list of PSNP kebeles in each of the two selected woredas.

The participants interviewed were purposefully identified and recruited based on their positions and roles in the implementation of PSNP and linkages with health services in the study sites.

Study participants were the agriculture and health sectors focal persons at the regional, woreda and kebele levels:

- Sectoral focal points for health and agriculture at the Regional Level

- Woreda Health Officer (WoHO) and Agriculture officers at the woreda level

- Development Agent (DA) and Health Extension Workers(HEWs) at the kebele level

- Temporary Direct Support (TDS) beneficiaries ( pregnant women, lactating women and caretakers of children with malnutrition

\section{Data collection:}

Data was collected through in-depth interviews and focus group discussions (FGDs). The in-depth interviews aimed at assessing the linkage between PSNP and health services.

Interview guide with semi-structured interview questionnaire was used to obtain information on a range of issues about PSNP implementation and linkages with health services from the participants.

- The study participants during the Key informant interviews were asked about their knowledge and roles in the transition of eligible households to TDS clients from public works, the co-responsibilities of the beneficiaries and barriers to effective linkages. This was done at the region, two woredas and six kebeles.

- The FGDs was conducted in the six selected kebeles among the TDS clients and assessed their knowledge about their rights, selection process and co-responsibilities and their participation as required.

- The study was conducted in between March and April 2021 and The FGDs and KII were audio-taped and notes were also taken with prior consent from the participants.

Data Analysis. The FGD and KII data collected from different categories of respondents and responses to the same questions were triangulated and transcribed verbatim to produce transcripts of narrative text for thematic analysis. The data were coded according to the types of themes and issues and thematic analysis was used which comprised a mix of inductive and deductive coding.

The primary outcome of the study is identifying factors related to the linkage of the PSNP beneficiaries to the health services and the implementation of the co-responsibilities by TDS clients.

These co-responsibilities include a list of activities that client households are expected to undertake, but receipt of payments under PSNP4 is not meant to be conditional on whether the client household has met it co-responsibilities.

These co-responsibilities include the following requirements ${ }^{1}$ :

- Pregnant women should attend four antenatal care visits; women should complete one visit to the health post six weeks after birth: 
- Lactating women with a child less than one year old: attendance at one post-partum health facility visit; follow recommended immunization schedules for infants and attendance at growth monitoring and promotion/behavioural change communication sessions.

- Primary caregiver of a malnourished child under five years old during treatment are attend the clinic monthly to complete the treatment (e.g. community management of acute malnutrition or targeted supplementary feeding) as advised.

\section{Results}

The results are organized in two major themes: Process involved in the linkages between PSNP and health services for the temporary direct support (TDS) clients and barriers to effective linkages.

Section 1: Stakeholders knowledge about the linkages between PSNP and health services - this focused on the knowledge and roles of the stakeholders at the regional, woreda and kebele levels about the process for transition of eligible households to temporary direct support (TDS) clients from public works and the co-responsibilities of the beneficiaries.

\subsection{Knowledge and role in transition of eligible households to temporary direct support (TDS) clients}

The Key informants were asked about their knowledge and roles in the process for transition of eligible households to temporary direct support (TDS) clients. All the key informants interviewed were familiar with the recommended process and their roles in the transferring of pregnant and lactating women and households with children with malnutrition from the public work to temporary direct support clients which exempt them from the public work. However, there was variation in their knowledge about the exact duration the TDS clients are to be exempted from public work as detailed in the project implementation manual (PIM).

\section{Regional perspective:}

Even though actual implementation of linkage is done at the kebele level, however the regional and woreda team are involved in the process and expected to provide needed monitoring and support to ensure this is effectively done.

'PSNP is a multi-sectoral project in its nature and has relations with health, and when a mother is around three months pregnant, she contacts the DA who completes a form and that allows the pregnant mother to get a leave from the public work until her return when her child gets $10 \mathrm{months}$ old. This linkage exists at regional, woreda and Kebele level.'

\section{(Regional Key Informant 1)}

\section{Woreda Perspective}

'At the community level there is DA and HEW assigned in each kebele to implement the linkage but the woreda health office and the agriculture office provide support to the kebele level team in ensuring linkages between the PSNP and health services.'

( Woreda key Informant 1)

'Actually, the health office is more involved with the Temporary direct support group where we support at the kebele level with the identification of the eligible beneficiaries (pregnant, lactating and Households who have malnourished children).'

( Woreda Health Office Key Informant II)

\section{Kebele perspectives}

Generally, the role of health extension workers (HEWs) is to identify pregnant women, lactation women and households of children with malnutrition who are engaged in public work and provide letter upon confirmation in the health facilities to the Development Agents so they can be exempted from public works. The Development agents who keep the names of all PSNP beneficiaries are to effect their transfer to temporary direct support groups and continue to provide them with the support throughout the duration until they return back to public work. However, the DAs and HEWs interviewed provided different expected duration of exemption from public works.

'As the development agent, my role is to check and follow up to see that TDS beneficiaries ( Pregnant and Lactating women and households with child with malnutrition) are transferred from public work into TDS category and still get their support which PSNP gives them.'

$$
\text { ( Development Agent Key Informant 1) }
$$

'My role is to connect the variety of categories like the Public Work, TDS, and the Permanent Direct Support in the community to the health centre and the project activities as well. I engage in encouraging them to connect the health centre and receive health services.'

(Development Agent Key Informant 2)

'When pregnant women tell us that they are pregnant or we notice it ourselves, we asked them to bring confirmation letter from the health facility and based on that we exempt them from public work.' 
(Development Agent Key Informant 2)

'As a Health extension worker, my role is to register the lactating, pregnant mothers and malnutrition children and send them to the DA to transfer them until 6 months after they deliver, and the child is cured from malnutrition.'

$$
\text { ( Health Extension Worker Key Informant 1) }
$$

'As HEW my responsibility is that when mothers realize they are pregnant they come to me ,I give them a confirmation letter which will be used to exempt her from working during her pregnancy and six months after delivery.'

( Health Extension Worker Key Informant 2)

'When mothers claim to be pregnant it's our task as HEWs to confirm their pregnancy and then write confirmation report to the kebele DA for the project to transfer the status of the pregnant women to TDS group and exempt them from work until a year after delivery.'

( Health Extension Worker Key Informant 3).

\subsection{Knowledge about the co-responsibilities of temporary direct support (TDS) clients/}

The Key informants were aware the Temporary direct support (TDS) clients are supposed to participate in some activities referred to as co-responsibilities in replacement of the public work. However, they did not appear to have more precise knowledge of co-responsibilities about clients' specific obligations other than the general advice of coming to the health facilities, but the schedules and number of visits expected not well articulated

The development agents and health extension workers are expected to orientate the TDS beneficiaries about their co-responsibilities as detailed in the PIM and follow them up to monitor compliance.

However, after linking them up with the development agents who registers them, they do not follow strictly to monitor the co-responsibilities but manage them like other patients who are to come to the health facilities routinely.

\section{Kebele perspective}

"Once we transfer them and exempt them from public work, they are to be seen and monitor by the health workers in the clinics to ensure they go to the clinic regularly to receive services."

$$
\text { ( Development Agent Key Informant } 1 \text { ). }
$$

'It is the responsibility of the HEWs to monitor their attendance in the clinic, we don't work in the clinic, we only keep their record of transfer and provide them with the money and other supplies monthly services.'

$$
\text { ( Development Agent Key Informant 2). }
$$

"They are supposed to come to the clinic regularly to receive ANC, immunization for themselves and post-natal visit for their pregnancy can progress very well and their child since they are exempted for work so should have time to come regularly.'

(Health Extension Worker Key Informant 1)

'The mothers of malnourished children are to attend OTP clinic regularly and give their children plumpy nuts as provided for them.'

$$
\text { (Health Extension Worker Key Informant 2) }
$$

'There is no special clinic for them, we are busy, so we attend to them like other patients when they come and sometimes, they don't come to the clinic again. We don't have a special register for them.'

(Health Extension Worker Key Informant 3)

'Anytime the pregnant and lactating women or malnourished children come we provide them with health awareness and all the services and drugs they need and ask them to always come back.'

(HEW Health Extension Worker Key Informant 4)

'Many only come to the clinic so they can be given letter to stop working but later they don't come to the clinic and we are busy to follow them to their house, some of them leave very far.'

(Health Extension Worker Key Informant 5)

\subsection{Knowledge of the TDS clients about their rights, selection process and co-responsibilities}


The knowledge of the pregnant women, lactating mothers and mothers of children with malnutrition seen during the various focus group discussions( FGDs) show that they are aware of the process for identification of households eligible to be excluded from the public work and transferred to the TDS categories and still receive their monthly benefits both money or food or other materials.

"When a woman gets pregnant, she comes to the hospital for the nurse to confirm her pregnancy and give her a letter to the DA and then she will not work again until baby reaches two years and she will still continue to collect the money even though not working.'

$$
\text { ( FGD participant I) }
$$

"When we become pregnant, we become free from the public work until we give birth and that child become one year, after that we return back to the public work.'

(FGD participant 2)

"When the women is lactating and breastfeeding her children she is given a free service and not expected to work in the public work, also she gets the payment and other supportive and need materials, she has been getting even though she is not working in the public work."

(FGD participant 3)

"When a malnourished child is seeing in the clinic, the mother will be given a letter so the family will be free from the public work until the child recovers so they can have time to treat their child, and they will get the payment without working.'

$$
\text { (FGD participant 4) }
$$

\subsubsection{Knowledge of the temporary direct support(TDS) clients about their Co-responsibilities}

Most of participants in the focus group discussions were not aware of the specific obligation and required number of visits to the health facility for their co-responsibilities in lieu of the public work other that the general advice on health seeking behaviour and clinic attendance for relevant services.

'We are expected to participate in different community awareness related activities and attend immunizations before and after delivery for our children and ourselves.'

$$
\text { (FGD participant 1) }
$$

'We are expected to go to the health clinics always to see the health workers to monitor us and our babies, to deliver in the health center and to participate in different meeting and awareness creation of the project.'

$$
\text { (FGD participant 2) }
$$

'We are to continue to breast feed our children and keep ourselves and environment clean and take them for immunization in the health centers regularly until we go back to public work.'

$$
\text { (FGD participant 3) }
$$

'We take our children with malnutrition to the clinic in our kebele regular to receive plumpy nuts until the child is ok or if not ok, they will transfer us to the woreda health centre to continue treatment.'

$$
\text { (FGD participant 4) }
$$

'Sometimes we don't go to the clinic regularly because the clinic is far from our house and no means of transportation in our area.'

$$
\text { (FGD participant 5) }
$$

'There is no specific time to go to the clinic but regularly for immunization or for nutrition clinic for malnourished children and antenatal care or when our children are sick.'

(FGD participant 6)

\section{Section 2:}

1. The barriers to effective linkages between the PSNP and health services; this focused on identification of barriers to effective linkages by the stakeholders at all levels.

Most of the barriers/challenges to the linkages were expressed by the woreda key informants and this ranges from poor coordination and communication between the key actors( HEWs and DAs), poor knowledge due to lack of training on the project especially clear guideline to clarify the expected role of each of the actors especially in reference to the monitoring of the beneficiaries. Other barriers mentioned included lack of dedicated budget for the health sector either to follow up and monitor the compliance, no clear guideline on reporting template or mechanism for the co-responsibilities and limited access to health 
services for TDS beneficiaries who live far from health centers or in kebele with no health facilities. Some also mentioned that the project is seen and being implemented more as belonging to the agricultural sector and not as a key element of local development planning as designed.

\section{Regional perspective:}

'There is poor awareness and capacity regarding linkage between the two sectors. There is lack of clear and simplified linkage guides for DA, HEWs and woreda steering committee on implementation of the linkages.'

\section{( Regional key Informant 1)}

"The DAs and HEWs are expected to monitor the TDS clients to ensure they fulfil the obligation even tough without any sanction, but the record is kept at the kebele level, we don't include this in our report at the regional level but we have noticed that there is poor documentation system at woreda and kebele level about the TDS record of compliance.'

( Regional Key Informant 1)

'Except participating the meeting there is no intersectoral collaboration between PSNP and regional/ woreda health offices, there is no regular weekly, monthly, or quarterly coordination platform to discuss PSNP performance at regionally.'

\section{( Regional key Informant 3)}

'There is no adequate knowledge about the project, many people see it in different administrative people think that PSNP project is owned by agriculture bureau only.'

$$
\text { (Regional Key Informant 4) }
$$

\section{Woreda perspective:}

'The understanding of the project as we know PSNP is multi-sectoral project it has effect on different offices but we think it is only part of agriculture office who get the capacity buildings and other benefits of the project so it has to be shared with the other offices.'

(Woreda Health Office Key Informant 1)

'It seems there is no enough awareness and understanding /complete information about the project among the stakeholders and the beneficiaries especially about the role expected by each person for effective linkage of the PSNP with health services.'

(Woreda Health Office Key Informant 2)

\section{Kebele perspectives:}

'Development Agents and health extension workers in each kebeles are responsible for the monitoring and flow up the beneficiaries after being transfers to TDS category but this doesn't usually happen because the HEWs are always busy.'

$$
\text { (Development Agent Key Informant } 1 \text { ) }
$$

"Sometimes the health team do not participate in our meeting and so not aware of many things we do and can't get report from them about the TDS clients they see in the clinic.'

$$
\text { ( Development Agent Key Informant 2) }
$$

"Some of the pregnant women or malnourished children are from kebeles or sub kebele where there are no health facilities and have to travel a lot distance which sometime make them not to come to the nearest health facilities and difficult to follow them up.'

$$
\text { (Health Extension Worker Key Informant 1) }
$$

'We don't have regular meeting with the PSNP team to discuss about the issues of the health services we provide for the beneficiaries which would have been a good opportunity for better working relationship and understanding of the problem we face.'

(Health Extension Worker Key Informant 2)

"We don't have fund to move around in the budget to follow up the TDS clients if they don't come, no good communication with the PSNP team, we have not been trained on the project unlike the DAs and no reporting format to be used for recording our activities and share.'

$$
\text { (Health Extension Worker Key Informant 3) }
$$

\section{Discussion}

The transition of the eligible pregnant and lactating women and households with children with malnutrition from public work to temporary direct support category and implementation of the co-responsibilities( soft conditions) are key components of the linkage between PSNP and health services. 
The study observed that the stakeholders have adequate knowledge and understand their roles in the linkages between PSNP and the health services through the temporary direct support clients, in addition the beneficiaries also are aware of their rights and the process for transitioning .However the major issues are the poor coordination at the kebele level among the implementing actors, poor knowledge, monitoring and compliance with the co-responsibilities by the stakeholders and the TDSs clients which is the crux of project so as to improve demand and utilization of services for better maternal newborn children health and nutrition outcomes.

The study shows that the selection of the beneficiaries was adequately done and no problem or complaint by the beneficiaries this is unlike in a study ${ }^{16}$ on safety net program in some countries in Latin America and the Caribbean, which reviewed linkage between conditional cash transfer program and health services and reported poor identification of beneficiaries as one of the major problem in the project.

Our study found weak coordination among the key actors at all level in terms if planning, joint monitoring, report sharing and participation in coordination meetings. This seems to be a major problem in many interventions that requires multisectoral collaboration, the finding in our study is similar to findings from other studies in interventions that involved multisectoral collaboration that also observed poor coordination among the implementers especially at the community level even though they reported better coordination at the central level. A study ${ }^{17}$ in Malawi that looked at integration of intervention to improve nutrition outcomes found strong multidisciplinary interaction exists at central levels but not at the community level, this is similar to study ${ }^{16}$ on improved linkages between conditional cash transfers and reproductive health programs in Latin America and the Caribbean that reported limited integration at the subdistrict level among the various actors and suggested increase supervision by Regional team needed to ensure effective linkages. A land scape analysis ${ }^{18}$ done in 19 countries that assessed the extent of agricultural investments contribution to nutrition outcome noted that strong collaboration observed at the higher policy level ,national coordination and district coordination levels does not extend to the community level in most of the countries studied and provided practical guidance on how to initiate and manage multi-sectoral approaches and improve coordination and collaboration across a range of stakeholders.

The focus of the PSNP in linkage can only be achieved if the co-responsibilities are adhered to which is aimed at ensuring pregnant and lactating women and children with malnutrition have access to regular health services to improve maternal newborn child health and nutrition and reduce defaulter among children seeking nutrition and immunization services especially in a region like Somali with poor health and nutrition indices. However, our study found out that knowledge of the stakeholder and TDS beneficiaries about the co-responsibilities( soft conditions) is poor. In addition, there is no established follow up or monitoring, or reporting mechanism to monitor compliance. Some of the factors mentioned responsible for this included work overload by HEWs, limited or no budget/operational/logistic support for the HEWs for follow up and monitoring.

As found in our study, these respondents both the health workers, the development agents and the TDS clients did not appear to have more precise knowledge of co-responsibilities in terms of the specifics apart from the general advice for health seeking behaviour, this is similar to finding from earlier studies ${ }^{15,19}$ in Ethiopia which reported imperfect understanding among woreda and kebele staffs and beneficiaries did not have adequate knowledge on co-responsibilities especially on the specific obligations of the beneficiaries. A similar review study ${ }^{16}$ on conditional cash transfer and linkage with reproductive health reported that in many of the countries evaluated , a large proportion of program beneficiaries were not aware of, or did not know about, all or even some of the conditions for to be fulfilled in receiving payments. However, an intervention study 20 in Ethiopia where social workers were engaged to follow up and monitor compliance to co-responsibilities of beneficiaries, found that the knowledge and compliance to co-responsibilities was higher among those in intervention area compared to the control group with no active follow up or monitoring of compliance.

Our study found out that there is no or limited monitoring of compliance to co-responsibilities by the TDS clients with associated risk of not being able to achieve the objective of exemption of the TDS beneficiaries from public work and help improve maternal newborn and child health and nutrition outcomes. A study ${ }^{21}$ on conditional cash transfer shows that only if the conditionality is monitored and compliance enforced will it have an effect and found that similar to our study in some conditional cash transfer programs, compliance were not necessarily being monitored. The study noted that in conditional cash transfer programs where there was effective monitoring, compliance was found to be extremely high by up to 94 percent of households and reported that in cases without monitoring the evidence of the impact of the program was mixed. A study by Morris et al (2004) ${ }^{22}$ found null effects in the Honduran conditional cash transfer program where conditionality was not enforced and noted that unless adequate measures are put in place to monitor compliance the program beneficiaries will not comply with program conditions and suggested joint review adherence to the co-responsibilities by all stakeholders to be part of the activities in the project cycle.

One of the major barriers to monitoring of the compliance to co-responsibilities and poor intersectoral collaboration at the kebele level by the HEWs is the workload especially in health posts where mostly only one health extension worker is assigned as result of increase demand and responsibilities expected from HEWs( monitor co-responsibilities, provide services for the PSNP client, follow up ) in addition to the routine activities in the clinics. A previous study ${ }^{19}$ in Ethiopia also identified human resource shortage with too few staff with heavy workloads as factors that constrained the program implementation by reducing the ability of the Health extension workers to conduct home visits and monitor compliance to the co-responsibilities.

This is similar to findings in previous studies ${ }^{23,24}$ which found that community health workers performance is affected by workload, number of tasks, the size of the catchment area, organization of tasks and proposed that community health workers have manageable workload in terms of a realistic number of tasks and clients, an organized manner of carrying out these tasks and a reasonable geographic distance to cover.

A study ${ }^{17}$ in Malawi on the integration of community health workers from different sectors reported the integration was affected/limited by workload and suggested a need to have a liaison officer who should track integration of the activities.

The use of social workers to track and monitor implementation of integration was found to be effective in as previous study 20 in Ethiopia which showed improved multisectoral collaboration among social workers and local development agents, health extension workers, which improved client fulfilment of co- 
responsibilities in health compared to where social workers were not engaged.

Access to health services by the temporary direct support beneficiaries especially those who live in kebeles/sub kebeles where there are no health facilities or those who live far from the nearest health facilities and requiring to travel from a long period of time was reported to be another barrier to compliance with coresponsibilities. This is similar to a study ${ }^{17}$ on conditional cash transfer program which identified access to health services by beneficiaries as a major challenge in effective linkage between the program and health services and implemented various strategy including use of mobile team and use of NGOs to provide services to the population including home visits and follow up which improved access to services and ensure better results.

A study ${ }^{20}$ in Ethiopia shows that temporary direct support beneficiaries who were aware and able to fulfil their co-responsibilities said that they had been able to do so because their health posts were near their homes and provided good services.

Other concern raised by the health extension workers affecting their performance and for effective intersectoral collaboration and follow up, monitoring and reporting compliance to co-responsibilities was lack of funding allocated to the health sector for logistic or operational support including inadequate transportation unlike the agriculture sector. A previous study ${ }^{19}$ in Ethiopia also identified inadequate transport support as being responsible for infrequent visits by the HEWS to conduct home visit of monitor compliance especially in remote communities.

This is similar to other studies ${ }^{25,26}$ that review the practical implication of linkages between agriculture and health sector which reported that funding and budget controls as the core reason why there was little interaction between the two sectors. A similar study 27 in Ethiopia also identified lack of resources within individual sectors as barriers to effective coordination between health and agriculture and these studies recommended development of joint work plan with budget allocated for all activities to be implemented by both sectors for effective integration of intervention.

Another barrier to effective linkage and multisectoral collaboration reported in our study is the perception by the respondents in health sector about the PSNP being seen as a project that solely belong to the agriculture sector and that the success will be attributed to the sector because this is managed as vertical program and not included as part of the responsibilities of the health workers in the woreda plan. This is similar to finding in a study ${ }^{26}$ that assessed the role of agriculture program in improving nutrition outcome which identified sector mandate and priorities as one of the barriers to integration because for the individual civil servant working within the confines of a sector ministry or agency, personal incentives like career advancement tend to revolve around their contribution to that attainment of narrowly sector-specific objectives.

Another study in ${ }^{27}$ Ethiopia on linkages between health and agriculture sectors also identified presence of competing priorities within individual sectors as barriers to effective coordination between the two sectors and the studies recommended inclusion of the integrated activities in the workplan or deliverables of the staffs in the health and agriculture sectors.

\section{Limitation of the study}

The study couldn't report on the number of temporary direct clients who adhered to co-responsibility and effect on utilization of health services because of no available data at the time of the study. The findings in our study is also subject to response biases since we rely on the information provided by the respondents.

We suggest further study to look at the effect of compliance with co-responsibilities by the beneficiaries on the utilization of services and health and nutrition outcomes we suggest a future research to look at the effect of the on utilization of services and also cost effective.

\section{Conclusion}

The Productive Safety net program which is the main tool to help forward Ethiopia's Social Protection Policy and Strategy, has the potential to improve maternal newborn and child health and nutrition outcomes if more efforts are put to strengthen integration and linkages with the health sector and monitoring of compliance of co-responsibilities by the temporary direct support beneficiaries of the program. Considering the size of the program in the region targeted to the poor, the benefits of improving linking the beneficiaries clients with health services could be decisive for the government and all stakeholders in the region. The focus should be beyond coordination but deliberate pursue of collaboration among agriculture and health sectors especially at the kebele level which will involve sharing of resources and enhancing one another's capacity for mutual benefit and to achieve a common purpose in addition to exchanging information and altering/ synchronization of activities. The development and deployment of a management information system to provide timely data about temporary direct support beneficiaries and improved monitoring systems would help strengthen the linkages.

\section{Declarations}

Acknowledgement: The authors wish to thank Abdirahman Ahmed and Ahmed Tahir from the Jijiga University who coordinated the field work and data collection. We also thank all the enumerators and all the individuals interviewed during the field work at the Regional, woreda and kebele levels.

\section{Funding Source: NONE}

Disclosure: Authors have declared that no competing or potential conflict of interests exist. The findings of this study and recommendations arising from this study are the sole responsibility of the authors and do not represent the position of the organizations they work for.

Authors Contributions: Conceptualization: Oladeji $O$ and Elmi Farah A; Data Curation: Oladeji $\mathrm{O}$ and Elmi Farah A; Formal analysis: Oladeji O; Original Draft: Oladeji O; Review and final draft: Oladeji O, Elmi Farah A, Robins A, 


\section{References}

1. Government of Ethiopia. Productive safety net programme phase IV: programme Implementation Manual. Ministry of Agriculture (Ethiopia), Addis Abab; 2014. Available at https:// www.usaid.gov/sites/default/files/documents/1866/psnp_iv_programme_implementation_manual_14_dec_14.pdf

2. Ethiopia Central Statistical Agency, ICF. mini Ethiopia Demographic and Health Survey 2019. Addis Ababa, Ethiopia, and Rockville, Maryland, USA, 2019.

3. Bassett L. Can conditional cash transfer programs play a greater role in reducing child undernutrition? (English). Social Protection discussion paper 2008 ; no. SP 0835 Washington, D.C. : World Bank Group. http://documents.worldbank.org/curated/en/484651468140967937/Can-conditional-cash-transferprograms-play-a-greater-role-in-reducing-child-undernutrition

4. Bhutta ZA, Ahmed T, Black RE, Cousens S, Dewey K, Giugliani E et.al. Maternal and Child Undernutrition 3: What Works? Interventions for maternal and child undernutrition and survival, The Lancet 2008; 371:417-440 : :https://doi.org/10.1016/S0140-6736(07)61693-6

5. Rasella D, Aquino R, Santos CA, Paes-Sousa R, Barreto M. Effect of a conditional cash transfer programme on childhood mortality: a nationwide analysis of Brazilian municipalities, The Lancet,2013;382:57-64. DOl:https://doi.org/10.1016/S0140-6736(13)60715-1

6. Alderman H, Ruel M. Nutrition-sensitive Interventions and Programmes: How Can They Help to Accelerate Progress in Improving Maternal and Child Nutrition?, The Lancet 2013; 382: 536-551.DOI:https://doi.org/10.1016/S0140-6736(13)60843-0

7. de Groot R, Palermo T, Handa S (2017): Cash Transfers and Child Nutrition: Pathways and Impacts Development Policy Review 2017;35(5): 621-643,

8. Debela B, Shively G, Holden S. Does Ethiopia's Productive Safety Net Program improve child nutrition? Research Gate 2015 September https://www.researchgate.net/publication/281859704_Does_Ethiopia's_Productive_Safety_Net_Program_improve_child_nutrition

9. Porter C, Goyal R. Social protection for all ages? Impacts of Ethiopia's Productive Safety Net Program on child nutrition. Social Science \& Medicine 2016; (159): 92-99 https://www.sciencedirect.com/science/article/abs/pii/S0277953616302106

10. Berhane G, Hoddinott J, Kumar N. The impact of Ethiopia's productive safety net programme on the nutritional status of children, 2008-2012. IFPRI discussion paper series IFPRI, Washington D.C (2017) Google Scholar

11. Gilligan D, Arrieta A, Devereux S, Hoddinott J, Kebede D, Ledlie N et.al. Integrating Service Delivery with Cash Transfers to Improve Nutrition in Ethiopia: An Impact Evaluation of the IN-SCT Pilot Project in Oromia and Southern Nations, Nationalities, and Peoples' Region POLICY BRIEF.UNICEF 2018. https://www.unicef.org/ethiopia/media/3431/file/Integrating\%20Service\%20Delivery\%20with\%20Cash\%20Transfers\%20to\%20lmprove\%20Nutrition\%20ir

12. Gebrehiwot T, Castilla C( 2018):Do safety net transfers improve diets and reduce undernutrition? Evidence from rural Ethiopia Journal of Development Studies 2018:1-20, 10.1080/00220388.2018.1502881CrossRefGoogle Scholar

13. Bahru BA, Jebena MG, Birner R, Zeller M.Impact of Ethiopia's productive safety net program on household food security and child nutrition: A marginal structural modeling approach.SSM Popul Health 2020;(12);100660: https://doi.org/10.1016/j.ssmph.2020.100660

14. World Bank. Making Services Work for Poor People. World Development Report 2004. Washington, DC: World Bank. https://openknowledge.worldbank.org/handle/10986/5986. accessed 23th September 2020

15. Berhane G, Birch I, Cabral L , Gillian D. The Productive Safety Net Programme 4 Midline Survey 2018 Program Performance Report: International Food Policy Research Institute and Institute of Development Studies, University of Sussex April 2019

16. Ricardo V , Rivero-Fuentes ME. Assessing the need and opportunities for improved linkages between conditional cash transfers and reproductive health programs in Latin America and the Caribbean," FRONTIERS 2008 Final Report. Washington, DC: Population Council.

17. Phuka J, Maleta K, Thomas M, Melisa Gladstone M. A job analysis of community health workers in the context of integrated nutrition and early child development. Ann. N.Y. Acad. Sci. 2014;1308: 183-191: Issue: Integrating

18. SPRING. Operationalizing Multi-sectoral Coordination and Collaboration for Improved Nutrition: Recommendations from an in-depth assessment of three countries' experiences. Arlington VA: Strengthening Partnerships, Results, and Innovations in Nutrition Globally (SPRING) 2016.

19. Roelen K, Devereux S, Kebede D , Ulrichs M. Cash 'plus' - Integrated Nutrition and Social Cash Transfer (IN-SCT) Pilot in Ethiopia: perceptions and feedback from clients and service providers. Research Report 2017. Institute of development studies (IDS) and Centre for Social Protection, UK https://opendocs.ids.ac.uk/opendocs/handle/20.500.12413/13469

20. UNICEF, MOLSA and IFPRI. Impact Evaluation of Improved Nutrition through Integrated Basic Social Services and Social Cash Transfer Pilot Program (INSCT) in Oromia and SNNP Regions, Ethiopia: End-line Impact Evaluation Report 2020.

21. Glassman A, Todd J, Gaarder M. Performance-Based Incentives for Health: Conditional Cash Transfer Programs in Latin America and the Caribbean CGD Working Paper \#120 April 2007 Global center for development https://www.cgdev.org/sites/default/files/13542_file_CCT_LatinAmerica.pdf

22. Morris S, Flores R, Olinto P, Medina JM.. "Monetary incentives in primary health care and effects on use and coverage of preventive health care interventions in rural Honduras: cluster randomized trial," The Lancet 2004; 364: 2030-2037.

23. Bhutta ZA, Lassi ZS, Pariyo G, Huicho L. Global Experience of Community Health Workers for Delivery of Health-Related Millennium Development Goals: A Systematic Review, Country Case Studies, and Recommendations for Integration into National Health Systems. Geneva: WHO/Global Health Workforce Alliance 2010.

24. Jaskiewicz W, Tulenko K. Increasing community health worker productivity and effectiveness: a review of the influence of the work environment. Hum. Resour. Health 2012,10: 38.

25. Shenggen F, Pandya-Lorch R. Reshaping Agriculture for nutrition and health. International Food Policy Research Institute(IFPRI) 2020. Editors DOI : http://dx.doi.org/10.2499/9780896296732 https://ebrary.ifpri.org/digital/collection/p15738coll2/id/126825.

26. World Bank. From Agriculture to Nutrition : Pathways, Synergies and Outcomes. Washington, DC. (c) World Bank 2007. https://openknowledge.worldbank.org/handle/10986/28183 License: CC BY 3.0 IGO 
27. Ayana G, Hailu T, Kuche D, Abera A, Eshetu S, Petros A et.al .. Linkages between health and agriculture sectors in Ethiopia: a formative research study exploring barriers, facilitators and opportunities for local level coordination to deliver nutritional programmes and services. BMC Nutrition 2017; 3:69 DOI 10.1186/s40795-017-0189 